\title{
HOMOSOCIALIDAD Y SECRETISMO EN LA EXPERIENCIA DE LOS HOMBRES QUE CONSUMEN PROSTITUCIÓN EN ESPAÑA
}

\section{Beatriz Ranea Triviño}

\section{Resumen}

El consumo de prostitución es una práctica masculina que trasciende la individualidad de los sujetos que la llevan a cabo, ya que ha de ser conectada con la construcción de la masculinidad y los rituales de confraternización sobre los que se articulan estas experiencias. El consumo de prostitución para muchos hombres se constituye como un ritual grupal de la masculinidad y, para otros, adquiere carácter colectivo cuando la experiencia es compartida a través de la narración vinculada al secretismo del pacto entre caballeros. Para dar cuenta de la homosocialidad y del secretismo que gira en torno las experiencias de los hombres que consumen prostitución, se presentan resultados de investigación cualitativa en la que se han realizado entrevistas en profundidad a hombres que han consumido prostitución femenina en España.

Palabras clave: Masculinidad, prostitución, homosocialidad, secreto.

\section{Resumo} \section{Espanha}

Homossocialidade e sigilo na experiência de homens que usam a prostituição em

O consumo da prostituição é uma prática masculina que transcende a individualidade dos sujeitos que a praticam, devendo ser associada à construção da masculinidade e aos rituais de confraternização nos quais essas vivências se articulam. $O$ consumo da prostituição para muitos homens constitui-se como um ritual grupal de masculinidade e, para outros, adquire um caráter coletivo quando a experiência é compartilhada por meio da narração vinculada ao sigilo do acordo de cavalheiros. Para dar conta da homossocialidade e do sigilo que giram em torno das experiências de homens que usam a prostituição, são apresentados resultados de investigação qualitativa na qual foram realizadas entrevistas em profundidade com homens que usaram a prostituição feminina em Espanha.

Palavras-chave: Masculinidade, prostituição, homossocialidade, segredo.

Universidad Complutense de Madrid, 28040 Madrid, España.

Dirección postal: Facultad de Ciencias de la Información, Universidad Complutense de Madrid, Sección Departamental de Sociología Aplicada - Av. Complutense, 3, 28040 Madrid, España.

Correo eletrónico: b.ranea@ucm.es 


\begin{abstract}
Homosociality and Secrecy in the Experience of Men who Pay for Prostitution in Spain

Paying for prostitution is a male practice that transcends the individuality of the subjects who carry it out, since it has to be connected with the construction of masculinity and the fraternization rituals in the context of which these experiences occur. The consumption of prostitution for many men is a group ritual of masculinity and, for others, it acquires a collective dimension when the experience is shared through narration linked to the secrecy of the gentlemen's agreement. In order to explain the homosociality and secrecy involved in the experiences of men who pay for prostitution, this paper presents the results of a qualitative research study which included in-depth interviews with men who payed for female prostitution in Spain.
\end{abstract}

Keywords: Masculinity, prostitution, homosociality, secret.

\title{
Introducción
}

Según los datos macrosociales disponibles en España, el 32\% de los hombres ha pagado por prostitución alguna vez en su vida, mientras que sólo el 0,1\% de las mujeres lo había hecho (CIS, 2009)ํ․ Por esto, abordaremos la prostitución como una práctica masculina y, en concreto, en este artículo se reflexiona sobre el carácter colectivo de la misma y el secretismo sobre el que se construye.

Así, se analiza la prostitución como una práctica masculina que para muchos hombres adquiere un carácter de ritual grupal, bien porque la práctica prostituyente se lleva a cabo de forma colectiva, o bien porque adquiere ese carácter colectivo cuando es narrada a otros hombres. De esta forma, la práctica cobra un significado grupal tanto cuando se va en grupo como cuando es relatada de unos hombres a otros.

Este carácter grupal nos permite interpretar la prostitución como una experiencia homosocial en la que se representa la masculinidad hegemónica frente al grupo de iguales (Flood 2008). La homosocialidad vertebra el aprendizaje, la construcción y reafirmación de la masculinidad. Los hombres que aparecen en los discursos de los entrevistados, o bien son referentes que les enseñan sobre sexualidad, o bien son pares con los que comparten experiencias narradas o vividas: hablan de prostitución con ellos o bien acuden a prostitución con ellos. Se puede afirmar que existe cierta presión grupal (Banyard 2017) porque si el mandato grupal anima a consumir prostitución, aquel que se niegue no será reconocido como un auténtico hombre, ni será reconocido como parte del grupo de iguales. De tal manera que, ante el grupo de pares, uno se comporta como el resto esperan que lo haga. La prostitu1 No contamos con datos al respecto desde 2009 y, por tanto, estos porcentajes pueden estar desac-
tualizados. 
ción cumpliría la función de afirmación del grupo de iguales del que, además, se excluye a las mujeres y, como se verá más adelante, el secreto compartido sirve para tejer vínculos entre los hombres, "al crear una dinámica grupal forjada en la clandestinidad, el secreto y la complicidad" (López y Baringo 2006, 18).

Cuando se realiza en compañía, el carácter performativo de la masculinidad adquiere aún mayor relevancia, pues el espacio de prostitución se convierte en un escenario de representación de la masculinidad frente al grupo de iguales, que le reconocen en tanto hombre a través de la práctica colectiva de instrumentalización y subordinación de las mujeres. Por ello, la identidad como clientes de quienes acuden en grupo se construye de forma colectiva. En este sentido, Silvia Chejter (2011) argumenta que la identidad del hombre se diluye en el grupo, en un nosotros que realiza la misma práctica.

El carácter grupal que adquiere la prostitución para muchos hombres permite que sea significada como un escenario de confraternización masculina, a través del cual los hombres generan ese sentimiento de ser parte de una amistad con otro amigo, un grupo de amigos o de compañeros de trabajo. En esta confraternización, como señala Flood (2008), las relaciones sexuales con mujeres son utilizadas por los hombres heterosexuales para generar lazos entre ellos. Es decir, compartir la experiencia en los espacios de prostitución y/o compartir la narración de la experiencia refuerza los vínculos masculinos heterosexuales. En estos ambientes homosociales se torna imprescindible demostrar la jerarquía respecto a las mujeres para mostrar la heterosexualidad. En la hermandad viril, donde los hombres que se reconocen frente a los otros y que son dotados de sentido de forma colectiva, a su vez necesitan a las mujeres como objetos (no sujetos) para mostrar que se alejan de la homosexualidad (que es representada como menos masculina). En las prácticas masculinas grupales es esencial contar con instrumentos para demostrar la auténtica hombría, como, por ejemplo, la violencia, la experiencia heterosexual o emociones como la rabia, la ira o el enfado. Si esto no sucede, el ambiente homosocial se relaciona con la homosexualidad. De esta manera, estos hombres desean estar con otros hombres, con sus iguales, pero han de hacer explícito que esta confraternización no tiene carácter (homo)sexual entre ellos. De ahí la importancia de los espacios de prostitución como escenarios de poder masculino donde, en principio, ninguno duda de la masculinidad (heterosexual) del otro.

De esta forma, "ir de putas" ${ }^{2}$ es un escenario perfecto para representarse como un auténtico hombre, encarnando la masculinidad hegemónica no cuestionada ni por el grupo de iguales que acompaña ni por las mujeres prostituidas. El cuerpo-objeto de las mujeres es representado como un instrumento para que los hombres se comuniquen entre ellos expresando su masculinidad. Es decir, se busca el reconocimiento del estatus de masculinidad hegemónica de los unos a los otros.

2 Se utiliza esta expresión tomada de los propios entrevistados y del argot de los grupos de hombres. 
Como señala Amorós (1992, 53), "[1]a mujer, como objeto transaccional de los pactos entre varones, cumple aquí una función especial en los rituales de confraternización de los pares". De esta manera, la mujer en prostitución se convierte en una mediadora simbólica entre los hombres, que, a través de su instrumentalización, reafirman su masculinidad a nivel individual y colectivo. El espacio de prostitución es percibido como un espacio homosocial en el que las mujeres aparecen como instrumentos también para sellar pactos entre varones.

Por todo lo expuesto, se puede hacer un paralelismo entre las tesis de René Girard (1983) y el significado de la prostitución en las sociedades contemporáneas, porque la mujer prostituida puede ser considerada una víctima propiciatoria en el ritual de la masculinidad. Girad expone que, cuando alguna comunidad entra en crisis, se incrementa la violencia, y aparecen ritos que, a través de víctimas propiciatorias, sirven para unir al grupo y establecer de nuevo el orden. De esta manera, ante los avances en igualdad de género y la incertidumbre identitaria masculina ${ }^{3}$, se necesitan mujeres como víctimas propiciatorias utilizadas en el ritual grupal de la masculinidad prostituyente para reconstruir el orden de género en términos patriarcales.

La prostitución se configura como un escenario en el que la fratría masculina representa su poder, a través de la segregación de género, pues las mujeres no vinculadas a la prostitución son vetadas de los espacios de prostitución. Las "afiliaciones horizontales" (Armstrong 1991, 91) masculinas se crean y se recrean en los escenarios de prostitución.

\section{Metodología}

Se trata de una investigación cualitativa en la que se llevaron a cabo 15 entrevistas $^{4}$ en profundidad a hombres consumidores de prostitución con diferentes perfiles sociodemográficos residentes en España. Las entrevistas proporcionaron gran cantidad de información sobre sus experiencias y percepciones en torno a la masculinidad en relación a la prostitución de mujeres.

Se considera relevante describir el proceso de búsqueda de entrevistados por la dificultad y complejidad del mismo. Investigar a hombres consumidores de prostitución es una tarea complicada, no sólo por las labores de contacto, sino también para conseguir cooperación por parte de ellos, muchos de los cuales desean permanecer ocultos y anónimos (Monto 2004). Por añadidura, al tratarse el consumo de prostitución de una práctica masculina, hay que tener presente que el género femenino de la investigadora supone una limitación para establecer con-

\footnotetext{
Lo que algunos autores denominan la crisis de la masculinidad. Anonimizadas.
} 
tacto, aunque también es una oportunidad para indagar sobre la influencia del género en las entrevistas 5 .

La selección de la muestra fue incidental, siguiendo criterios que nos permitieran recoger discursos de perfiles relativamente diversos entre los entrevistados, buscando hombres con diferentes características sociodemográficas (edades, profesiones, niveles de estudios, ingresos económicos, etc.) que acudieran a diferentes espacios de prostitución, con diferente frecuencia y concurrencia. Como investigación cualitativa no se busca la representatividad sino la relevancia de analizar estos discursos con el fin de detectar elementos y factores relevantes para comprender en profundidad los significados atribuidos por los entrevistados a sus experiencias en relación a la construcción de la masculinidad y el consumo de prostitución.

Debido a que los clientes de prostitución forman parte de una población invisible y oculta, con el fin de rentabilizar la obtención de la información, no se centró el estudio geográficamente ${ }^{6}$ en una región específica del territorio estatal, sino que se aceptó la participación de aquellos demandantes que se mostraron dispuestos a participar en las entrevistas.

Para buscar entrevistados se diseñó un cartel-anuncio solicitando participación, donde se recogía la información básica de la investigación, el teléfono y el e-mail de contacto. El cartel se difundió por listas de e-mail, se compartió en redes sociales y en foros de internet de usuarios de prostitución; se imprimió y colgó en zonas como Ciudad Universitaria de Madrid; y fue entregado en mano a hombres que acudieron a hacerse pruebas de VIH y otras ITS a una unidad móvil de una entidad social. El método con resultados más positivos para obtener participantes fue la bola de nieve entre contactos y entre algunos de los propios entrevistados, que compartieron la información a otros hombres potenciales participantes.

Se cerró el trabajo de campo con 15 participantes (que se corresponde con el número mínimo de participantes que se había establecido inicialmente como tamaño de la muestra).

Para profundizar en esto se recomienda el siguiente texto: Beatriz Ranea Triviño. 2020. “¿Qué hace una chica como tú en un sitio como éste? Mujeres investigando masculinidades: el caso de la demanda de prostitución". En Hombres, género y patriarcado: reflexiones, cuerpos y representaciones, coordinado por Anastasia Téllez Infantes, Javier Eloy Martínez Guirao y Joan Sanfélix Albelda. Madrid: Editorial Dykinson.

$6 \quad$ En cuanto a la diversidad geográfica, no se han encontrado diferencias significativas entre los discursos de unos entrevistados y otros respecto a las prácticas y las percepciones sobre las mujeres. La única diferencia hallada tiene que ver con la diferencia entre el medio rural y el medio urbano fundamentalmente en la accesibilidad a los contextos de prostitución, como se explicará en el análisis de las entrevistas. 
Tabla 1:

Perfiles básicos de los hombres entrevistados

\begin{tabular}{|c|c|c|c|c|}
\hline $\begin{array}{l}\text { Código } \\
\text { entrevista }\end{array}$ & Edad & Residencia & Nivel estudios & Ocupación \\
\hline E1 & 35 & Madrid & Formación profesional & Desempleado \\
\hline E2 & 34 & Jaén & Licenciado & Desempleado \\
\hline E3 & 34 & Argel y Badajoz & Arquitectura técnica & Aparejador \\
\hline E4 & 32 & Madrid & Bachillerato & Comercial \\
\hline E5 & 30 & Barcelona & $\begin{array}{l}\text { Diplomatura } \\
\text { (no especifica) }\end{array}$ & Comercial \\
\hline E6 & 44 & Gijón & $\begin{array}{l}\text { Diplomatura } \\
\text { (no especifica) }\end{array}$ & Recepcionista \\
\hline E7 & 29 & León & $\begin{array}{c}\text { Formación Profesional } \\
\text { Grado Superior }\end{array}$ & Desempleado \\
\hline E8 & 29 & Madrid & $\begin{array}{c}\text { Educación Secundaria } \\
\text { Obligatoria }\end{array}$ & Vigilante de seguridad \\
\hline E9 & 40 & Madrid & E.G.B. & Camarero \\
\hline E10 & 47 & Madrid & No contesta & $\begin{array}{c}\text { Director y actor } \\
\text { empresario de la } \\
\text { industria pornográfica }\end{array}$ \\
\hline E11 & 35 & Málaga & Licenciado & Estudia oposiciones \\
\hline E12 & 48 & Madrid & B.U.P. & Consultor \\
\hline E13 & 44 & Alcorcón & $\begin{array}{c}\text { Formación Profesional } \\
\text { Grado Superior }\end{array}$ & Desempleado \\
\hline E14 & 28 & $\begin{array}{l}\text { Pueblo de } \\
\text { Ávila }\end{array}$ & Posgrado (profesorado) & $\begin{array}{c}\text { Maestro de educación } \\
\text { infantil }\end{array}$ \\
\hline E15 & 38 & Madrid & Bachillerato & Conserje \\
\hline
\end{tabular}

En cuanto a la estructura del guion de las entrevistas, fue diseñado dividido en dos grandes bloques sobre percepciones y comportamientos sobre sexualidad y, por otro lado, percepciones y comportamientos sobre prostitución.

\section{Resultados y discusión}

\section{'Ir de putas' como ritual grupal masculino}

En el caso de las primeras experiencias en prostitución, para varios de los entrevistados, la propuesta de acudir a la prostitución proviene del grupo de igua- 
les masculinos o de algún referente masculino de forma individual. Así, hay que destacar la importancia de los referentes masculinos que aparecen en algunas de las narraciones y que son facilitadores que les introducen en los espacios de prostitución. Compartir la experiencia hace que la prostitución se convierta en un escenario ritual de reforzamiento del vínculo masculino. Esto es, se confraterniza mediante las enseñanzas y aprendizajes de otros miembros del grupo en los que mirarse y a los que no se desea defraudar. Estos hombres devienen demandantes de prostitución de forma grupal como herramienta de nexo entre ellos. Además, el consumo de prostitución aparece como un continuum en el que unos van introduciendo a otros.

[...] estábamos tomando copas en casa, aburridos la verdad, y fue como, fue otro que dijo ¿nos vamos de putas? Y dijimos pues sí, vámonos, ¡vámonos! ¡Venga, va, va! Que esto es un cachondeo, que no sé qué y no sé cuánto, las típicas cosas que hacemos los tíos absurdas y lo haces, ¿no? Y nos fuimos al Escorpio, llegamos al puticlub. (E3)

Comencé a consumir prostitución cuando trabajaba en una empresa de reparto de publicidad porque mis compañeros iban cada viernes. (E4)

La primera vez, primera, primera fui con amigo que me dijo: "ven, ven, ¿nunca has entrado en un sitio de éstos?" Y le dije: no. "Ven, ven". Y era un sitio, un bar, donde las tías estaban en bolas, solo con un tanga y las tetas fuera. Yo me quedé loco ¡hostia! Mira, mira que va con la teta fuera, ¿qué es esto? Yo aún conservo esa amistad, hace ya treinta años, y muy buena... Cuando salí de ahí dije: tengo la corazonada de que vamos a ser grandes amigos [se ríe]. (E10)

[...] un buen día, no sé, surgió la cosa, me iba más con un amigo más mayor, tenía coche, a lo mejor tenía él 26 y yo tendría 17 años, sí, era menor de edad y luego mi otro amigo me parece que tenía 18 años, y venga, tal, quedamos y fuimos ahí y lo hice y "oye, ¿qué tal?", bien, tal... (E8)

[...] me lo recomendó un amigo, me dijo: "vente conmigo, que verás", y efectivamente... Es una labor social y didáctica la que hicieron conmigo. Tuve suerte, ojo, porque yo también intenté hacer la jugada con otro amigo mío y salió fatal, fatal, fatal... Era una estúpida la tía y una borde y una... Y el pobre chaval salió traumatizado. (E13)

Por esto, la prostitución aparece como un escenario de confraternización de las masculinidades patriarcales. Las mujeres son mediadoras simbólicas entre los hombres:

[...] a lo mejor salía con un amigo y entonces, un día pagas tú, otro pago yo, y así como que te dolía menos. Y salíamos de fiesta, llegaban las tres [mira el reloj como simulando la situación] y decías vámonos [se ríe], y nos íbamos. Y la verdad es que como experiencia estaba muy bien, luego nos contábamos así las cositas y tal y estaba gracioso, ya no sólo por hacerlo sino por los momentos de contarnos las cosas, de colegueo y todo eso. (E8) 
Por otro lado, otros entrevistados relatan que tomaron la decisión de acudir a la prostitución tras leer las experiencias de otros hombres en foros de internet donde hombres prostituidores intercambian opiniones, experiencias, recomendaciones, etc. Los foros de internet se constituyen como comunidades virtuales que dotan también de un carácter colectivo a las experiencias de estos hombres, incluso cuando han acudido en solitario a la prostitución. Por ello, hay que destacar la relevancia de estas comunidades virtuales para leer las experiencias de otros demandantes y sentirse parte del grupo:

Internet me ha enganchado al porno, a las putis, a todo. Sí, porque es como que te lo normaliza todo, digamos, estás desde tu casita con tu ordenador pones porno y te sale hay un montón, todos los tipos de porno que existen y las putis pues empecé con una página web esta de uno que es un actor porno o no sé qué, empecé a ver experiencias y esto y me gustó. (E5)

[...] en internet en un foro había una chica que era masajista, no era prostituta si no que era masajista erótica [...] voy a Google, lo pongo a ver eso que era y ver el tipo de masaje que era. Entonces también venían resultados de los típicos foros en los que chicos cuentan su experiencia pues he ido a ver a esta chica y hemos hecho esto y esto, los típicos foros... (E11)

Asimismo, en los siguientes relatos se aprecia esa percepción de "ir de putas" como ocio masculino, vinculado a salir de fiesta con el grupo de amigos, acudir a la prostitución para terminar la fiesta, o con compañeros de trabajo al terminar la jornada laboral:

[...] en esos dos años que estuve sin pareja estuve igual haciendo uso de esto, me junté también con los amigos éstos que a lo mejor salíamos de fiesta y tal...

Entrevistadora: Salíais de fiesta y luego ¿a Casa de Campo?

No, eso ya íbamos a algún piso. Además, ahí ya empezó el declive de casa de Campo, empezaron a cerrarlo y se trasladaron a Marconi. Y ya digo, íbamos a algún piso, íbamos buscando las habichuelas. (E8)

[...] algunas veces voy con los amigos o voy solo. Normalmente en el trabajo, con algunos amigos, te vas con ellos, vas en el coche... Por ejemplo, este que te digo está en la carretera, yo no tengo coche así que me voy con algún amigo, con uno o dos. (E9)

El carácter ritual grupal de la prostitución es fundamental para comprender el significado de la misma en el contexto actual. Los espacios de prostitución se constituyen como masculinos y masculinizantes, donde la fratría no es interpelada, sino que se mueve de forma cómoda porque mediante el pago se minimiza la posibilidad de rechazo por parte de las mujeres. 


\section{El secreto de las experiencias en prostitución}

El secreto entre hombres vertebra las experiencias en prostitución porque esta práctica es compartida (casi) exclusivamente con éstos. De los 15 entrevistados, dos de ellos contestaron que no se lo habían contado a nadie; uno de ellos tan solo a una psicóloga; siete de ellos solo lo han compartido con otros hombres (normalmente amigos y/o compañeros de trabajo); tres lo han compartido con hombres y con "algunas amigas"; y dos de ellos se han expuesto públicamente contando sus experiencias (uno como gestor de un foro y personaje público en este sentido; el otro porque concedió una entrevista a un medio de comunicación). Por esto, podemos decir que prácticamente la mayoría de los entrevistados afirma que o no lo sabe nadie o solo tienen conocimiento de su práctica prostitucional otros hombres. Rostagnol (2011) se refiere al pacto de silencio entre los hombres en torno a la prostitución, ya que guardan el secreto entre unos y otros. De esta forma, el secreto y ese pacto de silencio entre el grupo de iguales sirve para reforzar los vínculos homosociales en torno a experiencias que no se comparten con mujeres no vinculadas a la prostitución.

En este sentido, es pertinente retomar a Georg Simmel $(2014,389)$ que destacaba la importancia del secreto en la configuración de las identidades tanto a nivel individual como colectivo. El secreto compartido es un nexo de unión grupal que les diferencia frente a las mujeres y genera un sentimiento de pertenencia a la comunidad masculina, a la fratría (Amorós 1990).

Además, la cuestión de los equipos que aborda Martin Criado (2014) es importante en este estudio, porque algunos de los entrevistados comparten experiencias en prostitución dependiendo del "equipo" en el que se encuentren. Si analizamos el caso de la familia, prácticamente ninguno de los entrevistados habla de prostitución en este ámbito, y si alguno lo ha hecho, ha sido siempre con la figura paterna - y, por tanto, con otro hombre - pero nunca con su madre. En cuanto a los amigos, alguno de los entrevistados hizo referencia a grupos de amigos con los que sí comparten estas experiencias, mientras que con otros no, especialmente, aquellos grupos de amigos en los que había mujeres. Todo esto se puede relacionar con el valor de los discursos en el mercado de interacción, tal como explica Bourdieu (2008), esto es, dependiendo de la interacción, exponer los discursos sobre sus experiencias en prostitución modifica el valor social de quienes producen ese discurso. Así, frente a otros hombres, compartir la experiencia sobre consumir prostitución puede tener valor en tanto en cuanto aumenta el reconocimiento de su estatus de masculinidad respecto al grupo de pares; sin embargo, frente a las mujeres, como se verá, no tiene ese valor y puede dañar su reputación.

Este secreto va unido al anonimato social, pues como se ha señalado con anterioridad, la mayoría de los entrevistados viven el consumo de prostitución desde el anonimato y se mostraron preocupados en cuanto que la entrevista pudiera quebrar su deseo de permanecer invisible. Como señala Susana Rostagnol 
(2011, 70), “[s]e observa entonces que el 'cliente' varón no solamente está comprando sexo, también compra certezas relativas fundamentalmente en torno a su no exposición pública, quien es pública es la mujer; nunca el varón".

La masculinidad no sólo es representada sino que también es discurso y, por tanto, a los entrevistados se les preguntó acerca de las personas de su entorno que tienen conocimiento de su actividad como consumidores de prostitución. Recogemos a continuación extractos de la masculinidad narrada, y de la confraternización que se realiza a través de la narración de las experiencias en prostitución con el grupo de iguales. Otros estudios destacan que la mayoría de los hombres o bien no se lo había contado a nadie, o bien lo comparten solo con otros hombres (Coy et al. 2007; Birch 2015).

Sí que es verdad que tengo algunos amigos que cuando hablamos de ello, hablamos con más normalidad que con otros que no van o que no lo cuentan... Pero no sé, es que tampoco me hablan mucho... A lo mejor me dicen: "hoy me he ido de putas"... (E1) [...] este tipo de conversación normalmente la tienen los pibes como un poco para sentirse como hostia, que machote, nos hemos ido de putas. (E3)

Lógicamente con los que más lo hablo es con los del trabajo y tal, si tú hablas muchas veces acaba saliendo por ellos solos. Yo un chaval del gimnasio me lo encontré en $E l$ Conejo ${ }^{7}$ ahora ya nos vamos ya por ahí con él, digo: ¿tú qué haces aquí? Todos vamos a lo mismo. (E9)

Tras este fragmento de la entrevista, dudó sobre si alguno de sus amigos acudía a la prostitución y añadió lo siguiente indicando que él inició a otro amigo en el consumo de prostitución. De tal forma que, como se ha señalado previamente, unos hombres inician a otros en el consumo de prostitución:

Tengo a uno que lo enganché hace unos años en el tema.

Entrevistadora: ¿Se lo dijiste tú?

Sí, le dije: pasa ya del tema, déjate de tal, de conquistarlas y que te cuenten su vida, que son muy pesadas y dije, le enseñé el loquo y tal y lo probó y le enganché y se metió al tema. Y después se fue a Londres y también probó algunas allí, pero... Ahora hace poco me dijo que se había hecho ya bastante rutinario y este era jovencillo, y normalillo, más o menos normal, la verdad es que no era un Brad Pitt [se ríe], pero bueno, es lo que hay... Mejor así, se lo pasa bien. (E5)

Respecto a si conocían a más hombres que consuman prostitución, todos menos uno de los participantes coinciden en afirmar que sí, es decir, otros hombres también han compartido la experiencia con ellos:

Nombre de un club de alterne. 
Ellos van más... Es diferente, sí que hacen cosas como yo pero sí que a lo mejor van a clubs y a pisos de estos, porque hay pisos en los cuales tú vas a cualquier hora y siempre hay chicas y te las presentan... (E1)

[...] algún amigo sí que lo ha dejado caer un poco así en algún momento sí. (E11)

No, se callan como putas [se ríe], alguno habrá pero... Además, es que yo en el trabajo vivo rodeado de millennials entonces supongo que existe algo así como la ficción tácita de que los jóvenes no van de putas porque no lo necesitan, ¿sabes? (E12)

En el contexto español, el dicho popular "callada como una puta" recoge la idea de que el pacto de silencio incluye también a las mujeres prostituidas, de las que se espera que no desvelen el secreto masculino.

Sí, esporádicas y alguna relación. Ahora estoy en una relación y vas a decir, ¡que cabrón! Porque sigo... Tengo confianza con las chicas... Una prostituta en un libro decía que ellas son las que más saben de los hombres, y no le falta razón porque a ellas les puedes contar todo, en las relaciones siempre hay cosas que no puedes contar. (E4)

Cuando se les preguntó si compartían la narración de la experiencia con las mujeres de su entorno, la mayoría contestaron que no. Se puede afirmar que este pacto sirve para reproducir la división de las mujeres entre públicas y privadas; donde las privadas no deben conocer lo que ocurre entre los hombres y las mujeres públicas. Hay que destacar que en los relatos de los entrevistados aparecen mujeres que fueron mencionadas como amigas, compañeras de trabajo, parejas de amigos o conocidas, y se observa la importancia de la reputación frente a estas mujeres no vinculadas a la prostitución, que son percibidas como posibles parejas sexuales en potencia. Por tanto, para salvaguardar su reputación frente a las mujeres privadas, a éstas no se les narra lo que ocurre con las mujeres públicas. Así, el hombre sigue manteniendo su reputación con las mujeres privadas. Estos hombres transitan entre las privadas y las públicas, pero excluyen a las mujeres privadas de lo que ocurre en la prostitución, de tal forma que actúan como agentes en la perpetuación de la heterodesignación patriarcal, la división entre las unas y las otras. En esta segregación por género, a una mujer en un clima de cierta confianza también se lo pueden reconocer, sobre todo, si no se trata de una mujer objeto de deseo. Reproducen una visión en la que una amiga, a diferencia de un amigo hombre, no deja de ser vista como una pareja sexual en potencia y, por tanto, protegen esa parte de su identidad porque si lo desvelan ponen en riesgo las posibilidades de mantener relaciones sexuales con esas mujeres. Así lo expresa en el estudio que realizó en Australia Philip Birch (2015), pues algunos de los participantes no comentaban con mujeres que ellos son demandantes de prostitución porque creían que eso influiría en que ellas tuvieran una visión negativa y limitaría sus posibilidades de mantener una relación convencional con ellas. En los siguientes fragmentos los entrevistados explican por qué no comparten la narración de la experiencia prostitucional con las mujeres: 
[...] mejor que no sepan nada, ellas me tienen que ver como un chico, tengo que aparentar, como un chico serio, formal, con valores [se ríe]. Luego si no, tú imagínate que traen a una amiga nueva al grupo, y tú quieres algo con ella pero le van a decir "ese es un putero", que bueno tampoco soy tanto pero... [se ríe] Entonces ya esa idea la tiene preconcebida la nueva chica que entra al grupo, y no va a querer hacer nada, entonces te estás cerrando puertas. Con un amigo no porque él también lo ha hecho y se va a callar porque si dice algo, tú vas a decir: ¡y tú también! [Se ríe]. (E8)

No, es que como yo tengo también el éste de que yo creo que a las chicas, a las mujeres esto no es una cosa que les guste mucho, entonces intento... No le voy a llegar y decir: "he hecho esto..." y van pensar que lo hago siempre y no es una cosa así. Que no es una cosa que diga... A una chica no se lo contaría. (E1)

A las que son amigas muy íntimas no, no lo saben, en general no voy contándolo ahí a todo el mundo porque a las chicas es un poco más delicado el tema, supongo no lo sé.

Entrevistadora: ¿Por qué dices que es más delicado?

Hombre porque [silencio]... Porque se dice de broma con los tíos estas cosas. (E5)

[...] a las amigas está descartado [...] Son gente muy heterogénea y les gusta hablar del tema, pero entre los chicos solo. Con las chicas nunca se habla de... [silencio]. (E7) [...] digamos que cuando he estado con las compañeras de trabajo, por ejemplo, no lo aceptan, se extrañan que tú te hayas ido con prostitutas [...] o lo viesen como algo malo. Por eso con mujeres no hablo de... (E9)

Además, como señala Sunderland $(2004,28)$, un discurso existe en tanto que es "socialmente reconocido" al menos por algunas personas que comparten ese marco de significados. Al tratarse de una práctica masculina, es un discurso socialmente reconocido y asociado al género masculino y se estima que no será reconocido ni entendido por las mujeres que son excluidas de estas prácticas y de los relatos sobre las mismas.

[...] aunque un hombre que no haya acudido nunca a estos sitios como que piensas, eres un hombre y me vas a entender de algún modo, eres un hombre y tienes necesidad entre comillas, lo que pasa es que esa necesidad cada uno la gestionará como crea conveniente pero como hombre sí me vas a entender. Pero a lo mejor con una mujer siempre existe esa cosa de no me va a entender, no va a entender esas necesidades masculinas. (E11)

Por otro lado, hay que destacar que los consumidores de prostitución reproducen los discursos normativos sobre la sexualidad masculina heterosexual y reafirman su masculinidad hegemónica en los contextos de prostitución; no obstante, algunos se conciben a sí mismos en tanto oprimidos o se comparan con grupos sociales que se encuentran en situación de desventaja social respecto a ellos. Como afirma Sabine Grenz (2005), los clientes de prostitución no pueden ser comparados 
con grupos oprimidos o subordinados socialmente porque el mero hecho de consumir prostitución es posible por la situación de privilegio social en la que se construye su subjetividad. Así, los participantes son hombres heterosexuales con el poder adquisitivo suficiente para materializar su deseo sexual de acceder a relaciones sexuales con mujeres.

Encontramos que algunos producen una inversión de significados en sus relatos, tratando de posicionarse en una situación de desventaja social en la que no se encuentran. Ellos no están en el mismo plano de la estructura social que las mujeres en situación de prostitución y ubicarse al mismo nivel es resultado de la negación de la desigualdad de género y la jerarquía en la que se construye la masculinidad frente a la feminidad. La inversión de significados les permite, de un lado, autopercibirse como parte de un grupo oprimido; y, por otro lado, desplazar la responsabilidad ante sus acciones y prácticas y no se hacen cargo de sí mismos, de su agencia, sus decisiones y sus comportamientos. Algunos se refieren al estigma que portan como consumidores de prostitución. No obstante, el estigma social tradicionalmente ha recaído sobre las mujeres. Las prostitutas han sido representadas a lo largo de la historia como desviadas, culpables de la prostitución, viciosas, pecadoras, han sido marginadas, estigmatizadas y tratadas como un riesgo para la salud pública y para la moral de la sociedad. Por el contrario, el hombre que deviene cliente de prostitución es percibido como un hombre que manifiesta el deseo sexual natural masculino. Además, las prostitutas han sido tradicionalmente quienes han portado la carga visible de la prostitución, mientras ellos han permanecido en el anonimato, como señala Marttila $(2008,38)$ : "[1]os distintos actores en prostitución, no tienen igual acceso a la invisibilidad", porque los clientes de prostitución sí tienen el don de la invisibilidad. Por tanto, no se trata de estigma para ellos, sino de la invisibilización del privilegio masculino. Esa invisibilidad les permite mantener su "reputación" frente a las mujeres privadas, es decir, la invisibilidad les permite mantener la posibilidad de caminar entre las mujeres privadas y las mujeres públicas. En este sentido, hay autoras como Osborne (2004) y Corso (2004) que hacen referencia al estigma del cliente, pero eso supondría admitir que el cliente está en el mismo plano social que la mujer y que la relación de prostitución se enmarca al margen de la estructura social. Es decir, esos planteamientos invisibilizan la desigualdad estructural de género y las relaciones de poder no sólo en términos de género sino también de clase y etnicidad que se (re)crean en los contextos de prostitución. La sociología ha de desvelar que la relación de prostitución no se produce entre dos individuos aislados, sino que dicha relación es un producto del contexto social desigual y, por ello, está imbricada en la intersección de desigualdades sociales que posibilitan su existencia.

Pero si vieras la persecución social que tenemos, es que me parece absurdo, una tía que tiene un pene en la boca, pues sí, pues sí, ¿qué me estás contando? ¿Hacer una ley porque esto es denigrante? (E2) 
Es como una especie de estigma que es sobre todo el cliente, ellas dicen las trabajadoras que también pero al cliente, te crujen vivo. (E2)

[...] si se quiere destruir a alguien en esta sociedad, no hay más que decir que ejerció la prostitución. Un reportaje de hace tiempo de investigación que se demostró que una famosa, Malena Gracia ejercía, y digo, ¿y a mí qué? Pero eso te jode, te destruye. O aquello que fue como muy escándalo, que salió Bisbal... Que a cualquier persona la relacionen aunque sea tangencialmente con esto... Hay gente que no le afecta, futbolistas del Real Madrid, que ya se sabe [se ríe], Benzema, Ribéry y todos estos que estaban, que además eso fue con esta chica que era menor. (E4)

Por último, tres entrevistados afirman que no se lo han contado a nadie de forma directa. Lo viven desde la vergüenza y la humillación de haber fallado de alguna manera al mandato de la masculinidad de encontrar una pareja sexual o porque hay cierta disonancia cognitiva entre sus actos y sus planteamientos a nivel ético, ya que entienden que consumir prostitución es éticamente reprobable.

No, no lo sabe nadie. Ni los amigos ni nada, en eso sí que soy un poco raro y preferiría que no lo supiera nadie [...] vergüenza a lo mejor, que parece que es siempre un tema tabú y que parece que es mejor que no se sepa ¿sabes? Yo por vergüenza y lo que fueran a decir al enterarse la gente, no sé. (E14)

No he sido capaz de contármelo a mí mismo de la forma en que lo hago ahora contigo, como para compartirlo con alguien, sea hombre o mujer. Yo no acepto a las personas que pagan por sexo. No creo que tenga justificación posible. No soy capaz de mirarme en un espejo y de decirme que soy un putero. Me parece un acto cruel, siempre, haya sexo o no. Hablarlo con alguien cara a cara sería... Exigiría más valor del que tengo. (E15)

\section{Conclusión}

El carácter colectivo del consumo de prostitución se articula de diferentes maneras: quienes visitan en grupo los espacios de prostitución; quienes leen y/o relatan las experiencias en comunidades virtuales masculinas como los foros para demandantes de prostitución; y para quienes narran las experiencias en prostitución con otros hombres, porque a través del relato también se dota a estas prácticas de un carácter grupal y se confraterniza con otros hombres. A través de los propios discursos de los hombres que han participado en la investigación que aquí se ha presentado, se da cuenta de la importancia del grupo de iguales que convierte la prostitución en una experiencia vivida de forma colectiva masculina. Asimismo, se ha hecho hincapié en el rol que juega el secreto para unificar al grupo ya que la mayoría de los hombres que han participado en este estudio viven el consumo de prostitución desde el anonimato social y el secretismo hacia las mujeres que no están vinculadas a la prostitución. 
El análisis del carácter colectivo del consumo de prostitución vinculado al pacto de silencio entre caballeros es fundamental para aproximarnos a la importancia del grupo de iguales masculinos en la reafirmación de la masculinidad, ya que será el grupo el que avale dicho estatus de masculinidad de cada uno de los miembros.

\section{Referencias bibliográficas}

Amorós, Celia. 1990. "Violencia contra las mujeres y pactos patriarcales." En Violencia y sociedad patriarcal, editado por Virginia Maquieira y Cristina Sánchez, 39-53. Madrid: Editorial Pablo Iglesias.

. 1992. "Notas para una teoría nominalista del patriarcado." Asparkía. Investigació feminista 1: 41-58.

Armstrong, Nancy. 1991. Deseo y ficción doméstica: una historia política de la novela. Madrid: Cátedra.

Banyard, Kat. 2017. Pimp State: Sex, Money and the Future of Equality. Londres: Faber \& Faber.

Birch, Philip. 2015. Why Men Buy Sex: Examining Sex Worker Clients. Nueva York: Routledge.

Bourdieu, Pierre. 2008. ¿Qué significa hablar? Economía de los intercambios lingüísticos. Madrid: Ediciones Akal.

Chejter, Silvia. 2011. Lugar común: la prostitución. Buenos Aires: Eudeba y Universidad de Buenos Aires.

CIS - Centro de Investigaciones Sociológicas. 2009. Encuesta Nacional de Salud Sexual. Madrid: CIS.

Corso, Carla. 2004. “Desde dentro: los clientes vistos por una prostituta." En Trabajador@s del sexo. Derechos, migraciones y tráfico en el siglo XXI, editado por Raquel Osborne, 121-134. Barcelona: Bellaterra.

Coy, Maddy, Miranda Horvarth, y Liz Kelly. 2007. 'It's just like going to the supermarket': Men buying sex in East London. Londres: Child and Woman Abuse Studies Unit, London Metropolitan University.

Flood, Michael. 2008. “Men, Sex, and Homosociality: How Bonds between Men Shape Their Sexual Relations with Women." Men And Masculinities 10(3): 339-359. DOI: https:/ / doi.org / 10.1177/1097184X06287761

Girard, René. 1983. La violencia y lo sagrado. Barcelona: Anagrama.

Grenz, Sabine. 2005. "Intersections of Sex and Power in Research on Prostitution: A Female Researcher Interviewing Male Heterosexual Clients." Signs 30(4): 2091-2113. DOI: https:/ / doi.org/10.1086/428418

López Insausti, Rafael, y David Baringo. 2006. Nadie va de putas. El hombre y la prostitución femenina. Zaragoza: Logi, Organización Editorial.

Martin Criado, Enrique. 2014. "Mentiras, inconsistencias y ambivalencias. Teoría de la acción y análisis de discurso." Revista Internacional de Sociología 72: 115-138. DOI: https:/ / doi.org/10.3989/ ris.2012.07.24

Marttila, Anne M. 2008. “Desiring the 'Other': Prostitution Clients on a Transnational RedLight District in the Border Area of Finland, Estonia and Russia". Gender, Technology and Development 12(1): 31-51. DOI: https:/ / doi.org/10.1177/097185240701200104

Monto, Martin A. 2004. "Female Prostitution, Customers, and Violence." Violence Against Women 10(2): 160-188. DOI: https: / / doi.org/10.1177 / 1077801203260948 
Osborne, Raquel. 2004. “Introducción.” En Trabajador@s del sexo. Derechos, migraciones y tráfico en el siglo XXI, editado por Raquel Osborne. Barcelona: Bellaterra.

Rostagnol, Susana. 2011. Consumidores de sexo. Un estudio sobre masculinidad y explotación sexual comercial en Montevideo y área metropolitana. Montevideo: RUDA-UNICEF.

Simmel, Georg. 2014. Sociología: estudios sobre las formas de socialización. México D.F.: Fondo de Cultura Económica.

Sunderland, Jane. 2004. Gendered Discourses. Hampshire: Palgrave Macmillan.

Beatriz Ranea Triviño. Profesora asociada de Sociología y Opinión Pública, Facultad de Ciencias de la Información, Universidad Complutense de Madrid. Doctora en Sociología y Antropología por la Universidad Complutense de Madrid con premio extraordinario de doctorado (2018/2019). Realizó el Máster Erasmus Mundus en Estudios de las Mujeres y de Género por la University of Hull (Reino Unido) y la Universidad de Granada. Autora del libro Desarmar la masculinidad (2021).

Correo eletrónico: b.ranea@ucm.es

Artículo recibido el 12 de Septiembre de 2020 y aceptado para su publicación el 05 de Marzo de 2021. 